\title{
Efficient determination of vehicle emission factors by fuel use category using on-road measurements: downward trends on Los Angeles freight corridor I-710
}

\author{
N. Hudda ${ }^{1, *}$, S. Fruin ${ }^{1, *}$, R. J. Delfino ${ }^{2}$, and C. Sioutas ${ }^{3}$ \\ ${ }^{1}$ Department of Preventive Medicine, Environmental Health Sciences, University of Southern California, \\ Los Angeles, CA 90089, USA \\ ${ }^{2}$ Department of Epidemiology, School of Medicine, University of California, Irvine, CA 92617, USA \\ ${ }^{3}$ Department of Civil and Environmental Engineering, University of Southern California, Los Angeles, CA 90089, USA \\ *These authors contributed equally to this work.
}

Correspondence to: C. Sioutas (sioutas@usc.edu)

Received: 5 June 2012 - Published in Atmos. Chem. Phys. Discuss.: 31 July 2012

Revised: 10 November 2012 - Accepted: 10 December 2012 - Published: 11 January 2013

\begin{abstract}
To evaluate the success of vehicle emissions regulations, trends in both fleet-wide average emissions as well as high-emitter emissions are needed, but it is challenging to capture the full spread of vehicle emission factors (EFs) with chassis dynamometer or tunnel studies, and remote sensing studies cannot evaluate particulate compounds. We developed an alternative method that links real-time on-road pollutant measurements from a mobile platform with realtime traffic data, and allows efficient calculation of both the average and the spread of EFs for light-duty gasolinepowered vehicles (LDG) and heavy-duty diesel-powered vehicles (HDD). This is the first study in California to report EFs under a full range of real-world driving conditions on multiple freeways. Fleet average LDG EFs were in agreement with most recent studies and an order of magnitude lower than observed HDD EFs. HDD EFs reflected the relatively rapid decreases in diesel emissions that have recently occurred in Los Angeles/California, and on I-710, a primary route used for goods movement and a focus of additional truck fleet turnover incentives, HDD EFs were often lower than on other freeways. When freeway emission rates (ER) were quantified as the product of $\mathrm{EF}$ and vehicle miles traveled (VMT) per time per mile of freeway, despite a twoto three-fold difference in HDD fractions between freeways, ERs were found to be generally similar in magnitude. Higher LDG VMT on low HDD fraction freeways largely offset the difference. Therefore, the conventional assumption that free-
\end{abstract}

ways with the highest HDD fractions are significantly worse sources of total emissions in Los Angeles may no longer be true.

\section{Introduction}

Monitoring of air pollution emissions from mobile sources is not only relevant to assessing the public health impacts of transportation, but also for evaluating the efficacy of regulatory measures and maintaining accurate emission inventories. In California, where mobile emissions are the single largest source of nitrogen oxides $\left(\mathrm{NO}_{\mathrm{x}}\right)$ and carbon monoxide $(\mathrm{CO})$ emissions, and therefore closely regulated, there is a particular need to accurately measure mobile emissions and trends.

Over the last two decades, gasoline-powered vehicle tailpipe and evaporative emissions have been targeted by multiple regulations (e.g., fuel reformulation, inspection and maintenance programs, tighter emission standards and better control technology) that have resulted in large reductions in light-duty gasoline vehicle (LDG) emissions. In the Los Angeles air basin, $\mathrm{NO}_{\mathrm{x}}$ and $\mathrm{CO}$ emissions (both tons per day and percent contribution) from light duty passenger cars (PC) have significantly decreased over the last decade. Notable regulations affecting fleet emissions during this time include the LEV ("Low Emission Vehicle" regulations, for 2003 and older cars) and LEVII (for 2004 to 2010 cars) that further 
tightened fleet emission standards and sharply reduced $\mathrm{NO}_{\mathrm{x}}$, $\mathrm{CO}$ and non-methane hydrocarbon emissions. In addition, fleet turnover to newer cars meeting OBDII requirements (On-Board Diagnostics) facilitated emissions control maintenance procedures and diagnostics. Based on California Air Resources Board estimates (CARB, 2009), despite increase in total $\mathrm{PC}$ activity, $\mathrm{PC}$ contributions to $\mathrm{NO}_{\mathrm{x}}$ emissions from mobile sources decreased from $34 \%$ in 2000 to $20 \%$ in 2010 , and they only emitted $40 \%$ as much CO in 2010 as they did in 2000. Consequently, heavy-duty diesel vehicles (HDD) became disproportionate contributors to on-road emissions (Harley et al., 2005) and a principal focus of regulations and control technology improvements. For example, from 2000 to 2010, heavy duty diesel trucks surpassed PCs as the top source of $\mathrm{NO}_{\mathrm{x}}$ (CARB, 2009).

In Los Angeles (LA), port-related diesel-engine activity has been the target of especially aggressive regulations at the Port of Los Angeles (PoLA) and Port of Long Beach (PoLB), such as the San Pedro Bay Ports Clean Air Action Plan (PoLA and PoLB, 2010a). These measures are expected to eliminate $72 \%$ of diesel particulate matter and $22 \%$ of $\mathrm{NO}_{\mathrm{x}}$ from port-related sources by 2014 (PoLA and PoLB, 2010b) through progressive bans on older engine years and by only allowing heavy duty diesel trucks meeting 2007 federal emission standards to operate on ports after 1 January 2012. Furthermore, the California Air Resources Board implemented drayage (short haul) truck regulations that required retrofitting with diesel particulate filters and that banned pre-1994 engines, with the expected benefit of accelerated fleet turn-over and $85 \%$ reduction in particulate matter emissions from trucks by 2013 (for engine years 1994 through 2006) (CARB, 2011a). Since these regulations are expected to have the largest impact on and near major port truck routes such as I-710, it was important to compare I710 HDD emissions to other freeways to ascertain if the additional fleet turnover incentives at the ports are having the desired effect.

Accurate emission factors (EFs) are challenging to determine but necessary for historical trend analysis. Of the studies that have quantified vehicle emissions trends in California, most have employed either tunnel measurements (Kirchstetter et al., 1999; Ban-Weiss et al., 2008, 2009, 2010) or the remote sensing approach (Bishop and Stedman, 2008; Bishop et al., 2010). Despite their merits, both of these approaches have significant limitations, summarized below, but described in more detail in Zavala et al. (2006) and Wenzel et al. (2000).

Tunnel studies in California have been most frequently conducted at the Caldecott Tunnel (Kirchstetter et al., 1999; Ban-Weiss et al., 2008, 2009, 2010), but results reflect the $4 \%$ upgrade, which increases engine load and emissions for HDDs, thus introducing a bias. Kean et al. (2003) conducted measurements at Caldecott tunnel and showed that driving uphill approximately doubled EFs for $\mathrm{CO}$ and $\mathrm{NO}_{\mathrm{x}}$ compared to the downhill direction. Furthermore, tunnel studies can only provide estimates of central tendency and not variability, as they report averages of large numbers of vehicles. Though the results are useful to evaluate fleet-wide average trend, without information on intra-fleet differences in EFs, it is not possible to determine whether reduction in vehicle emissions can best be achieved through targeting high emitters (e.g., drayage truck replacement) or fleet-wide measures such as new vehicle standards.

In contrast to tunnel studies, remote sensing allows determination of individual vehicle's $\mathrm{EF}$, but this technique is not mobile, so it can only make measurements at one location at a time, also a limitation unless large numbers of locations are sampled in a manner representative of real world driving modes. Moreover, it is applicable to only some gaseous pollutants. Bishop and Steadman et al. (2008) and Bishop et al. (2010) conducted remote sensing studies in West LA, and, more recently, at the Port of Los Angeles (Wilmington, CA) and Peralta weigh station (Anaheim, CA) (Bishop et al., 2012). In these studies, the West LA measurements were conducted on a traffic-light-controlled freeway ramp (I10/La Brea Ave) at a positive grade with reported mean vehicle speed less than 20 miles $^{-1}$ and acceleration greater than 1.9 miles $^{-1} \mathrm{~s}^{-1}$, i.e., conditions of high power. Similarly, heavy duty diesel trucks emissions were measured either at a zero grade, low speed, and high acceleration condition at the Port of Los Angeles or on a 1.8 degree incline with trucks in an accelerating mode at Peralta. Therefore, in these studies, high-load conditions likely biased EFs upward. Moreover, they measured EFs for just one, nearly instantaneous power level per vehicle, and did not measure within-vehicle variation in emissions across different power and speed conditions.

An alternative and arguably more efficient approach is using on-road measurements from real-world driving with a mobile platform, procedures similar to those used by Zavala et al. (2006, 2009) and Jiang et al. (2005). In this approach, ratios of pollutant concentration increase to $\mathrm{CO}_{2}$ concentration increase can be used to calculate both fleet EFs as well as individual vehicle EFs. Park et al. (2011), using the mobile platform approach in Los Angeles, found that inter-vehicle variability exceeded that due to different driving modes and that inter-vehicle variability in LDG EFs was less than that in heavy duty truck EFs. However, with numerous accelerations from arterial stop-lights and relatively little freeway driving, the Park et al. (2011) study did not provide representative coverage of HDD driving on freeways. Furthermore, the Park et al. (2011) approach of chase sampling individual vehicles provided only an instantaneous $\mathrm{EF}$ for each vehicle. These instantaneous EFs across vehicles were compared and conclusions were drawn regarding inter-vehicle variability even though EFs for different vehicles under different driving modes were being compared.

In a somewhat different approach (capturing vehicle plumes with a stationary set-up) Ban Weiss et al. (2009) made an important observation. They measured emissions 
from 226 individual vehicles and reported a large skew in inter-vehicle EF distribution, with the highest emitting $10 \%$ of trucks emitting $40 \%$ of total black carbon (BC) and particle number (PN) emissions. This suggests that studies extrapolating fleet-wide level emission inventories or trends based on individual vehicle measurements require large sample sets. This is cost prohibitive for dynamometer methods as well as vehicle chase techniques. In contrast, our study used a hybrid approach, combining individual plume impacts into longer averages that still managed to capture the spread and skew of individual EFs.

Our study had three main objectives. The first was to demonstrate that our hybrid technique captures a comparable or greater range of within-fleet variation in EFs compared to other methods, but in a more efficient manner by avoiding the need to analyze individual plumes and discard multiplume impacted data. The second objective was to evaluate the impact of recent HDD truck and port-specific regulations by measuring EFs that capture actual within-fleet variability by including a realistic mix of driving (e.g., speed and acceleration) and roadway conditions (e.g., grade). The third objective was to compare freeway emission rates (ERs) by taking total vehicle miles traveled into account, a potentially more direct means of evaluating relative impacts from different freeways.

\section{Methods}

\subsection{Mobile platform measurements}

A hybrid vehicle (2010 Honda Insight) was used as a mobile measurement platform. All the real-time instruments, listed in Table S1 in the Supplement, sampled air from a duct installed across the rear windows. The mobile platform was driven in "Green" mode which automatically turns off the engine when idling, eliminating the possibility of sampling its own emissions.

Several procedures were used to improve data accuracy. Data from instruments were aligned with respect to the fastest instrument to adjust for any delayed response after times were synchronized to be within $1 \mathrm{~s}$ to the Global Positioning System (GPS) device time (Garmin GPSMAP 76CSC). Instruments logged data at different intervals (1$10 \mathrm{~s})$ and all data were averaged over $10 \mathrm{~s}$. Freeway segments were demarcated in the $10 \mathrm{~s}$ data time series based on location information collected using the GPS. Quality assurance procedures included regular flow and zero reading checks.

For particle measurement instruments, several adjustments were necessary, a correction was applied to particle number concentrations exceeding $10^{5}$ particles $\mathrm{cm}^{-3}$ (similar to Westerdahl et al., 2005) reported by a Condensation Particle Counter (TSI CPC 3007) to account for coincidence. Black carbon (BC) data, collected using a Magee Scientific microAeth AE 51, was corrected for filter loading using the same techniques as Kirchstetter and Novakov (2007). The AE51 at short averaging times is susceptible to interference from vibration, and mechanical shocks result in sharp concentration spikes, usually large positive and negative pairs that last up to several seconds. The spikes were readily discernible because they exceeded the preceding and succeeding values by an order of magnitude and were unaccompanied by corresponding changes in concentration of other pollutants that correlate with BC. Such instances were identified and censored while processing the $\mathrm{BC}$ data, but data loss was less than $3 \%$.

Polycyclic aromatic hydrocarbons (PAH) were measured using PAS 2000 unit (EcoChem Analytics, League City, TX), which provides mass concentrations of particle-bound PAH species (PB-PAH). The instrument's response depends on physical characteristics of the particulate (size and shape) as well as the chemical composition of the PAHs. For example, benzo[a]pyrene with five rings produces a stronger photoemissions signal compared with particles coated with an equal mass of chrysene with four rings (Niessner et al., 1986). However, continuous PAH measurements using this instrument have been often used a "semi-quantitative" measure in roadway studies (for example, Marr et al., 2004). In these studies and ours, researchers have observed strong correlations between PB-PAH, BC and PN concentration (see Fig. S2 in the Supplement), indicating that PAH instrument response was approximately proportional to primary vehicle emissions over an order of magnitude change in concentration of $\mathrm{BC}$ and $\mathrm{PN}$.

\subsection{Sampling routes}

Emissions from motor vehicles were measured on five Los Angeles freeways - CA SR-110, I-110, I-405, I-710 and CA SR-91, highlighted in Fig. S1 in the Supplement. The mobile measurement platform was driven in the central lane of the freeway, when possible. HDDs are prohibited on the northern segment of I-110 (called CA SR-110), linking downtown LA to Pasadena and this northern segment was used to measure LDG-only emissions. Based on California Department of Transportation (CALTRANS) 2009 annual average daily traffic and truck data (counts of trucks 2-axle or higher), trucks constituted less than $1 \%$ of the total vehicle flow on SR-110. On southern I-110, the fraction was 5.0\% (CALTRANS, 2009), while freeways I-710, SR-91 and I-405 had 12, 7.6, and $3.8 \%$ truck fractions, respectively. Days and hours of sampling and meteorological conditions during the measurement period are summarized in Table S2 in the Supplement (Sect. S1). In general, sampling periods were well distributed to cover both rush and non-rush hour activity. 


\subsection{Mathematical calculations and equations}

\subsubsection{Emission factors (EF)}

Fuel-based EFs were calculated for every run at freeway segment level using a carbon balance approach, shown in Eq. (1):

$\mathrm{EF}=10^{3}\left(\frac{\Delta[P]}{\Delta\left[\mathrm{CO}_{2}\right]+\Delta[\mathrm{CO}]+\Delta[\mathrm{BC}]}\right) \times w_{\mathrm{c}}$

where EF is the emission factor ( $\mathrm{g}$ or particle number emitted per kg fuel burned) for pollutant $P, \Delta[P]$ is the median increase in the concentration of pollutant $P$ above the baseline roadway concentration $\left(\mathrm{g} \mathrm{m}^{-3}\right.$ or particle number $\left.\mathrm{m}^{-3}\right)$, and $\Delta\left[\mathrm{CO}_{2}\right], \Delta[\mathrm{CO}]$ and $\Delta[\mathrm{BC}]$ are the increases in the concentrations of the respective carbon combustion products above roadway baseline. All statistics (median or first percentile concentration) required to calculate EF using Eq. (1) were determined from the time series for each freeway segment, typically tens of miles long. If multiple runs were conducted on a freeway within a day, the time series for each run was analyzed separately. The mass fraction of carbon in fuel, $w_{\mathrm{c}}$, value was used as 0.85 for gasoline and 0.87 for diesel fuel (Ban Weiss et al., 2008). Fuel density values used were $0.74 \mathrm{~kg} \mathrm{l}^{-1}$ and $0.84 \mathrm{~kg} \mathrm{l}^{-1}$ for gasoline and diesel fuel, respectively, similar to other studies (Ban-Weiss et al., 2008). The values for fuel economy used in this study were 5.1 miles $^{-1}$ and 2.0 miles $^{-1}$ for LDG and HDD vehicles, respectively, based on Los Angeles fuel usage figures, obtained from CARB Emission Factors Model (CARB, 2011b). Therefore, this approach took differences in fuel density, carbon fraction, and fuel efficiency into account. More details are given in Sect. S2 in the Supplement, where corrections applied to fuel efficiency to meet the studies' assumptions have also been detailed (Table S3). Using mean square error propagation, the maximum uncertainty in EFs resulting from instrument accuracy, error in $\mathrm{CO}_{2}$ emission apportionment and error in HDD/LDG fraction of VMT was calculated. Values have been reported in Table 1 .

Roadway baseline values in Eq. (1) were estimated as the first percentile of pollutant concentrations observed on each freeway link. Since we attempted to measure concentration increases from traffic during a short time interval - over and above the elevated concentrations already present on the freeways - a low percentile value was the most appropriate indicator of baseline roadway concentrations. The lowest few concentration percentiles were relatively insensitive to superimposed traffic $\left(\mathrm{CO}_{2}\right.$ percentile profiles for a subset of runs have been plotted in Fig. S3 in the Supplement). Concentrations at a distant location away from the freeway were lower and would have provided an artificially low baseline estimate and upwardly biased the EFs.

A total of 25 runs were made on SR-110, which is the only thoroughfare with only LDG traffic in Los Angeles, and has been previously used for curbside measurements to study
LDG emissions (e.g. Kuhn et al., 2005a, b). We assumed that these 25 runs captured the expected spread of LDG emissions, based on the spread of EFs being comparable to that reported by other studies that measure individual LDG vehicle EFs. However, any error in adequately capturing the high end LDG emissions in these 25 runs would result in a misassignment of some fraction of LDG emissions to HDDs. With this LDG EF distribution, we then estimated total LDG emissions on other freeway links, and the remaining emissions were attributed to HDDs. This produced a distribution of possible HDD EFs for each of the 61 other freeway runs. Each run reflected a different fleet composition not only in terms of fraction that was HDD, but also a new set of vehicles under a new set of driving conditions.

\subsubsection{Real-time traffic characterization}

The total and hourly vehicle miles travelled (VMT) for HDD and LDG vehicles on each freeway link were obtained from aggregate data over all lanes of the freeway reported by the CALTRANS Performance Measuring System (PeMS) (Choe et al., 2002). These data are publicly available and give realtime traffic data averaged at nearly every mile on the segments studied. Further details are provided in Sect. S2 in the Supplement.

\subsubsection{Freeway emission rates}

Freeway emission rates (ERs), i.e., pollutant mass or particle number emitted per unit time per mile of freeway ( $\mathrm{g}$ or particle number $\mathrm{h}^{-1}$ freeway-mile ${ }^{-1}$ ) were calculated using Eq. (2), where $\mathrm{VMT}_{\mathrm{HDD}}$ and $\mathrm{VMT}_{\mathrm{LDG}}$ are expressed as vehicle miles travelled per unit time, normalized by freeway segment length (vehicle-miles $\mathrm{h}^{-1}$ freeway-mile ${ }^{-1}$ ); $\mathrm{EF}_{\mathrm{HDD}}$ and $\mathrm{EF}_{\mathrm{LDG}}$ are emission factors for pollutants per $\mathrm{kg}$ of fuel burned; $\mathrm{FE}_{\mathrm{HDD}}$ and $\mathrm{FE}_{\mathrm{LDG}}$ are fuel economies in miles $1^{-1}$; and $\rho_{\mathrm{g}}$ and $\rho_{\mathrm{d}}$ are fuel densities expressed as $\mathrm{kg}^{-1}$.

$$
\begin{aligned}
& \mathrm{ER}=\mathrm{VMT}_{\mathrm{HDD}} \times \mathrm{EF}_{\mathrm{HDD}} \times\left(\frac{1}{\mathrm{FE}_{\mathrm{HDD}}}\right) \times \rho_{\mathrm{d}}+\mathrm{VMT}_{\mathrm{LDG}} \\
& \times \mathrm{EF}_{\mathrm{LDG}} \times\left(\frac{1}{\mathrm{FE}_{\mathrm{LDG}}}\right) \times \rho_{\mathrm{g}}
\end{aligned}
$$

\section{Results and discussion}

\subsection{LDG fleet emission factors}

LDG EFs on SR-110 showed about an order of magnitude range, as shown in Fig. 1. This variation was due to differences in speed (also shown in Fig. 1), acceleration, grade, and inter-vehicle variability. We assumed this variability captured most of the same sources of LDG variability as on other freeway segments, as shown in Table 1. The resulting EF distributions generally span the range reported by Park et 
Table 1. Emission Factors for LDV and HDV fleet. Values have been reported as average \pm standard deviation.

\begin{tabular}{|c|c|c|c|c|c|c|c|}
\hline & & Year & $\mathrm{NO}_{\mathrm{x}}{ }^{1}$ & NO & $\mathrm{PN}^{2}$ & $\mathrm{BC}$ & PAH \\
\hline & Units & & g kg-fuel $^{-1}$ & g kg-fuel ${ }^{-1}$ & particles-m ${ }^{-3} \mathrm{~kg}_{\text {-fuel }}{ }^{-1}$ & $\mathrm{~g} \mathrm{~kg}$-fuel $^{-1}$ & $\mathrm{~g} \mathrm{~kg}$-fuel $^{-1}$ \\
\hline \multirow{5}{*}{ LDG } & SR-110 & 2011 & $3.8 \pm 1.4$ & $2.0 \pm 0.8$ & $4.3 \pm 2.6 \times 10^{14}$ & $0.07 \pm 0.05$ & $0.0008 \pm 0.00006$ \\
\hline & Park et al. $(2011)^{5}$ & 2007 & $9.4(2.5-5.7)$ & \multirow{4}{*}{$3.8 \pm 0.3$} & $6(1.5-5.2) \times 10^{14}$ & $0.06(0.01-0.03)$ & \\
\hline & Bishop et al. (2008) & 2008 & $5.9 \pm 0.4$ & & & & \\
\hline & Ban-Weiss et al. (2008) & 2006 & $3.0 \pm 0.20$ & & & $0.026 \pm 0.004$ & \\
\hline & Kirchstetter et al. (1999) & 1997 & $9.0 \pm 0.4$ & & $4.6 \pm 0.7 \times 10^{14}$ & $0.035 \pm 0.004$ & \\
\hline \multirow{10}{*}{ HDD } & $\mathrm{I}-710$ & 2011 & $15 \pm 9.2$ & $7.8 \pm 3.8$ & $4.2 \pm 3.4 \times 10^{15}$ & $0.41 \pm 0.21$ & $0.005 \pm 0.003$ \\
\hline & Other Freeways & 2011 & $16 \pm 10$ & $12 \pm 7.1$ & $5.2 \pm 3.1 \times 10^{15}$ & $1.33 \pm 0.33$ & $0.010 \pm 0.016$ \\
\hline & Dallmann et al. (2012) & 2010 & $28 \pm 1.5$ & $17 \pm 0.9$ & & $0.54 \pm 0.07$ & \\
\hline & Dallmann et al. (2011) & 2010 & $15.4 \pm 0.9$ & & & $0.49 \pm 0.08$ & \\
\hline & Dallmann et al. (2011) & 2009 & $25.9 \pm 1.8$ & & & $1.07 \pm 0.18$ & \\
\hline & Bishop et al. (2012) & 2010 & $47.8 \pm 0.6^{3}, 29.2 \pm 0.8^{4}$ & & \multirow{3}{*}{$4.5(0.71-1.4) \times 10^{15}$} & & \\
\hline & Park et al. $(2011)^{5}$ & 2007 & $34(6.8-17.6)$ & & & $0.5(0.07-0.17)$ & \\
\hline & Ban-Weiss et al. (2008) & 2006 & $40.0 \pm 3.0$ & & & $0.92 \pm 0.07$ & \\
\hline & & & \multicolumn{5}{|c|}{ Uncertainty in EFs } \\
\hline & & & $\mathrm{NO}_{\mathrm{x}}$ & NO & PN & $\mathrm{BC}$ & PB-PAH \\
\hline Instrument & & & $2 \%$ & $3 \%$ & $20 \%$ & $10 \%$ & $13 \%$ \\
\hline \multicolumn{8}{|l|}{ Accuracy } \\
\hline LDG & & & $4 \%$ & $5 \%$ & $20 \%$ & $11 \%$ & $13 \%$ \\
\hline HDD & & & $10 \%$ & $10 \%$ & $30 \%$ & $17 \%$ & $20 \%$ \\
\hline
\end{tabular}

${ }^{1}$ Reported as $\mathrm{NO}_{2}$ mass equivalent; ${ }^{2}$ Measured using TSI CPC $3007, D_{p}>10 \mathrm{~nm} ;{ }^{3}$ Port of LA measurements; ${ }^{4}$ Peralta weigh station measurements;

5 median (inter-quartile range).

al. (2011) for individual LDG vehicles. Results from other recent California studies are also plotted in Fig. 1.

Average EFs were generally in good agreement with recent studies (listed in Table 1). However, the mean values reported by remote sensing studies ("West LA", Bishop et al., 2008, 2010) were substantially higher than mean values in this study or Caldecott 2006 measurements, likely due to Bishop et al. (2010) measuring plumes from vehicles under strong acceleration. Furthermore, the standard error for EFs reported by Bishop et al. (2010) appears unrealistically tight. In contrast, the average EFs reported by the latest Caldecott tunnel study (Ban Weiss et al., 2008 and 2009; measurements conducted in summer 2006) agreed well with the mode of our EF distributions. However, they only captured a small fraction of the observed spread in EFs, as is expected from the well-mixed character of tunnel emissions.

\subsection{HDD fleet emission factors}

HDV emission factors (per kg fuel) exceeded LDV EFs by at least an order of magnitude for particulate pollutants and about four fold for $\mathrm{NO}$ and $\mathrm{NO}_{\mathrm{x}}$. On average the HDD fleet on freeways other than I-710 (the high cargo freight route, with results presented separately) emitted 4 times higher $\mathrm{NO}_{\mathrm{x}}, 10$ times higher $\mathrm{PN}$, and 6 times higher $\mathrm{BC}$ per quantity of fuel burned than LDGs. When differences in fuel efficiency were taken into account, the disparity between HDD and LDG emission factors further increased. Important statis- tics for HDV EFs are summarized in Table 1 and Table S4 in the Supplement.

Similar to the distributions for LDG EFs, significant variation was observed in HDD EFs, as shown in Fig. 2 (with the speed distribution in the last panel). Though the various study average EFs were in agreement, it is worth noting that our study appeared to capture much more variation in EFs than other studies, nearly an order of magnitude of real-world intra-fleet variation. It also did so in a more efficient manner i.e., without having to measure individual vehicles.

In absolute terms, HDD EFs had much broader variability than the LDG EFs. Combined with being an order of magnitude higher than LDG EFs, the variability in HDD EFs is therefore more consequential in determining the overall variability in fleet EFs.

In comparison to recent studies, the average HDD EFs in this study were lower. Colored bars in Fig. 2 represent results from the four most recent and relevant studies conducted in the state of California, measuring individual vehicle EFs (Ban-Weiss et al., 2009, 2010; Bishop et al., 2012; Dallmann et al., 2011). Numerical values have also been reported in Table 1 for comparison. Dallmann et al. (2011) measured EFs for individual vehicles in the Port of Oakland (Oakland, California) area and reported $\mathrm{NO}_{\mathrm{x}} \mathrm{EF}$ values around $15 \mathrm{~g} \mathrm{~kg}$ fuel $^{-1}$, in excellent agreement with this study. The remote sensing-based measurements of Bishop et al. (2012) at a location in the Port of Los Angeles, and at a truck weigh station (Peralta) on CA SR-91, were higher than $\mathrm{NO}_{\mathrm{x}}$ and NO EFs 


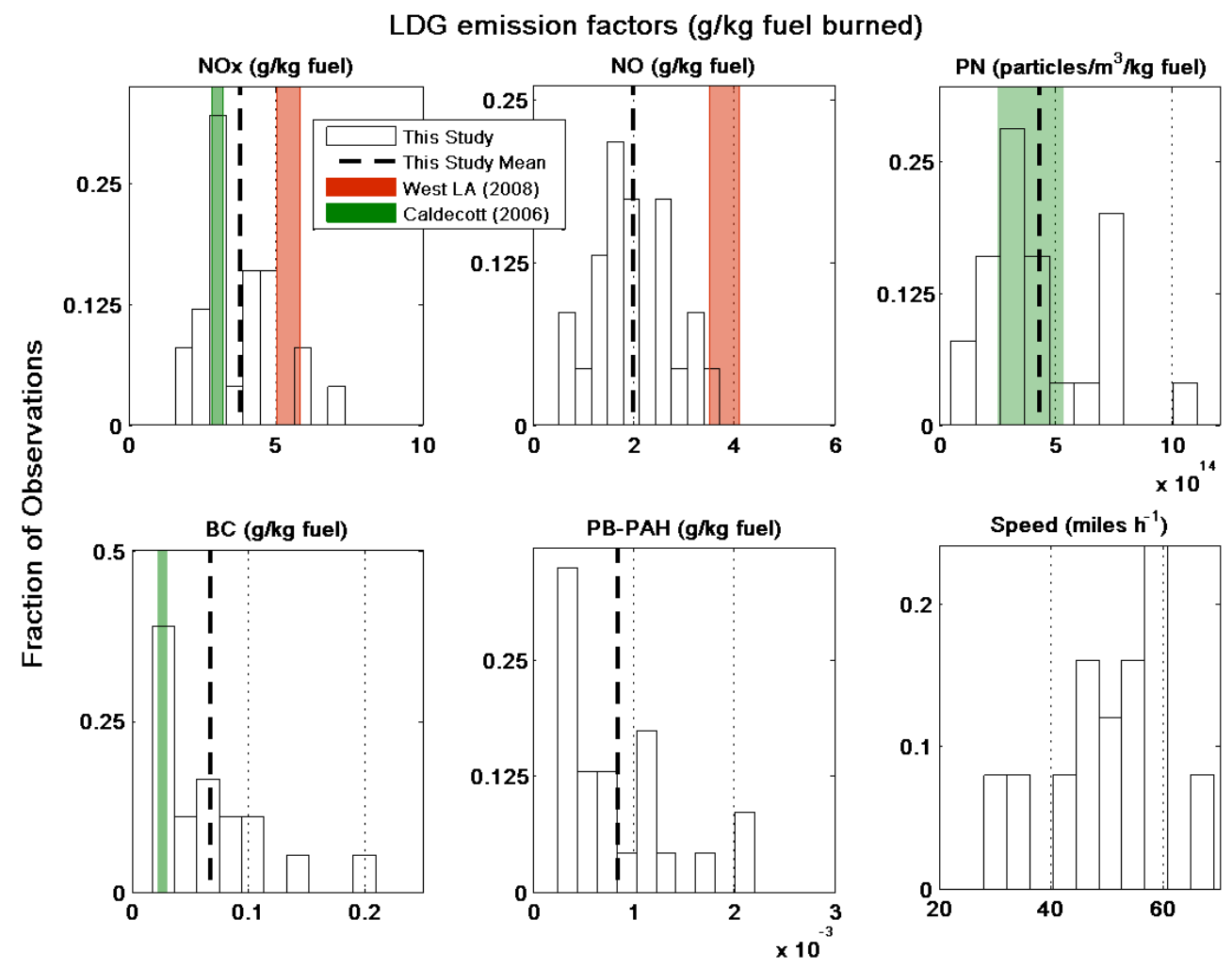

Fig. 1. LDG emission factors (measured on CA SR-110, total number of observations = 25). Caldecott (2006) refers to Ban-Weiss et al. (2008, 2010) results, and West LA (2008) refers to Bishop et al. (2010) results. The colored bars represent the reported one standard deviation range. Also note the exponents on the $\mathrm{x}$-axis for PN and PB-PAH EFs.

measured in this study, likely due to acceleration-only conditions. Though the PN EF mode agreed well with both Caldecott 2006 results (i.e., the fleet average and individual truck measurements-based mean) it is worth noting that due to the volatile nature of vehicle exhaust particles (especially ultrafine particles of diameter less than $100 \mathrm{~nm}$ ) and the markedly reduced dilution in tunnels, EFs measured in tunnel studies may not be a representative measure of real-world EFs.

Of all the pollutants measured, HDD fleet EFs were least skewed for $\mathrm{NO}_{\mathrm{x}}$ and $\mathrm{NO}$. EF skew in this study does not strictly result from only "high emitting" vehicles but a combination of vehicle differences and driving conditions. However, given that our calculated EFs were based on the median elevated concentration change on each freeway segment, they are less likely to be influenced by a transient driving condition like a hard acceleration and more likely to be influenced by sustained effects like the presence of a high emitting vehicle in the fleet-mix. This difference in distribution skews may have important implications for regulatory purposes - a substantial reduction in $\mathrm{NO}_{\mathrm{x}}$ and $\mathrm{NO}$ emission is probably more efficiently achieved through regulations aimed at lowering fleet-wide $\mathrm{NO}_{\mathrm{x}}$ and $\mathrm{NO}$ emissions, while control of $\mathrm{BC}$ or particle species emissions, with larger skews in EFs, are likely more effectively reduced by identifying and replacing or retrofitting specific high emitters.

\subsection{HDD fleet emission factors on I-710}

I-710 is a major route used for goods movement and the trucks involved are targeted by recent California Air Resources Board regulation efforts in addition to regulations by the ports themselves (i.e., Clean Air Action Plan). For this reason, it was useful to evaluate whether I-710 EFs might now reflect a newer, cleaner population of HDDs serving the ports compared to other freeways. Figure 3 shows that there is some evidence to support this. Though the spread of EFs on I-710 and other freeways was similar, lower EFs were observed more frequently on I-710. Median EFs on I710 were $50-70 \%$ of that on other freeways, although only the NO distributions were statistically significantly different (Kolmogorov-Smirnov test, $5 \%$ significance level). (Average HDD EFs are compared in Table S5.) Average NO EFs on I710 were about half of that observed on all other freeways, but $\mathrm{NO}_{\mathrm{x}}$ emissions were comparable. This suggests the $\mathrm{NO}_{2}-$ to- $\mathrm{NO}_{\mathrm{x}}$ ratio may have increased on $\mathrm{I}-710$, similar to that reported by Bishop et al. (2012) for Port of Los Angeles. Dallmann et al. (2012) also reported a negative correlation between trucks with highest $\mathrm{NO}_{2}$-to- $\mathrm{NO}_{\mathrm{x}}$ emission ratio and $\mathrm{BC}$ emissions, suggesting an association between trucks with diesel particulate filters and increase in $\mathrm{NO}_{2}$-to- $\mathrm{NO}_{\mathrm{x}}$ ratios. Continuously-regenerating particle trap technology has been 


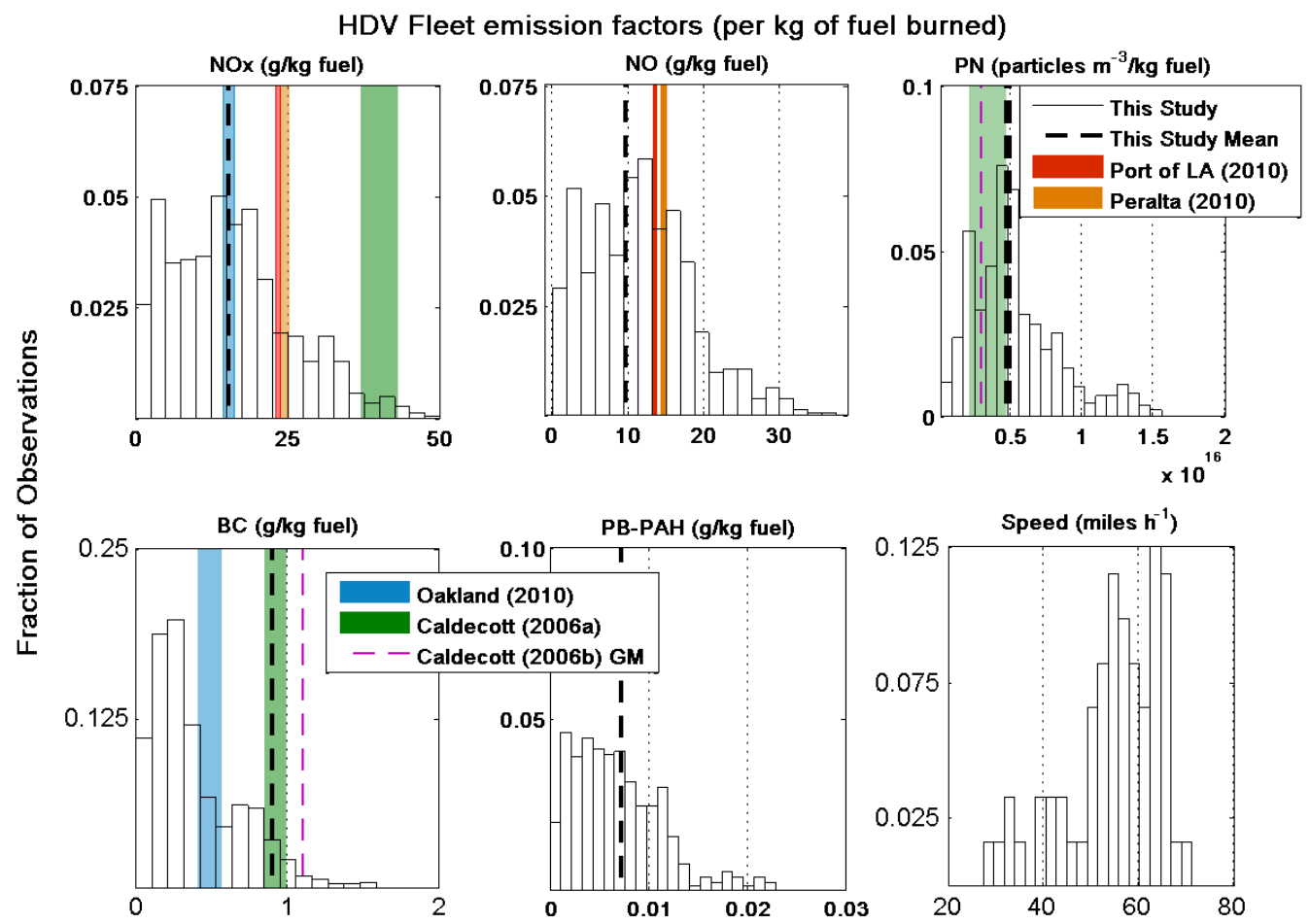

Fig. 2. HDD emission factors. Oalkand (2010) results represent individual vehicle plume averages reported by Dallmann et al. (2011), Caldecott (2006a) refers to Ban-Weiss et al. (2009) results, Caldecott (2006b) refers to Ban-Weiss et al. (2010) geometric means based on individual vehicles, and PoLA (2010) and Peralta (2010) refer to Bishop et al. (2012) results. Colored bars span the reported one standard deviation range. $\mathrm{BC}$ x-axis was truncated for clarity, values extend upto $15 \mathrm{~g} \mathrm{~kg}$-fuel $^{-1}$. Also note the exponent on the $\mathrm{x}$-axis for PN EFs.
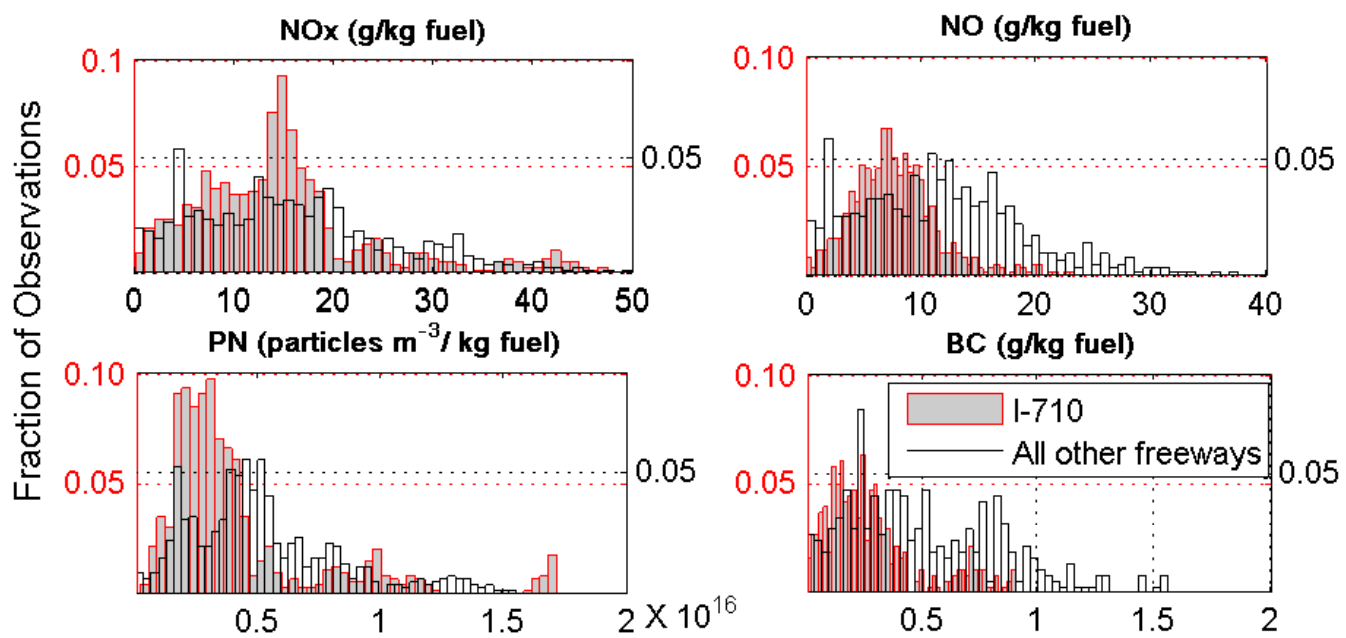

Fig. 3. Comparison of HDD fleet emission factors on I-710 to other mixed-fleet freeways (number of observations on I-710 $=32$, all other freeways $=29$ ).

reported to produce higher $\mathrm{NO}_{2}$-to- $\mathrm{NO}_{\mathrm{x}}$ fractions (Heeb et al., 2011; Velders et al., 2011). This finding may indicate that $\mathrm{NO}_{2}$ trends may no longer be a valid way to track reductions in diesel particulate matter emissions. For example, studies like Burnekeef et al. (2009) have used $\mathrm{NO}_{2}$ long-term trends as indicators of traffic particulate matter emissions.

\subsection{Freeway emission rates}

\subsubsection{Diurnal variation in freeway emission rates}

Total emissions from freeways depend not only on vehicle EFs but also vehicle miles traveled (VMT), which takes into 

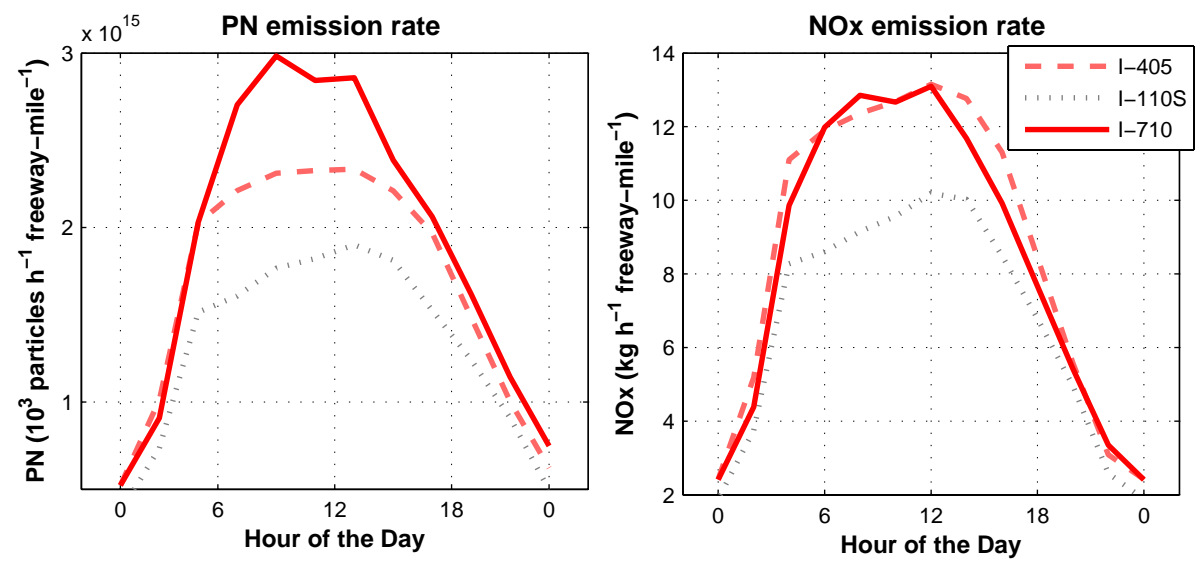

Fig. 4. Diurnal profile of I-110, I-710 and I-405 emission rates. 110S refers to I-110, the southern segment with mixed fuel fleet.

account variations in speed. VMT and its HDD fraction vary most with time of the day, and diurnal LDG activity patterns (either VMT or number of vehicles) are typically bimodal, peaking during morning and the afternoon rush hour. In Los Angeles, during midday (10:00-13:00 LT) a drop in LDG vehicle activity is often observed, more apparent in vehicle volume (number of vehicles per hour) than in VMT because higher non-rush hour speeds accumulate more miles (see Fig. S4 in the Supplement). However, HDD activity in Los Angeles increases and peaks during midday hours. The emissions from increased HDD activity seem to compensate for reductions in emission due to fewer LDG (or even a reduction in total VMT), thereby producing distinctly unimodal profiles for emission rates, such as shown in Fig. 4. Mean hourly VMT and HDD fraction on the freeway segments during the month May 2011 were used to generate Fig. 4. These diurnal patterns differ strongly from on-road or near roadway concentration profiles, which tend to be bi-modal as rush hour generally coincides with lower wind speeds and reduced dilution (Hudda et al., 2010; Ntziachristos et al., 2001).

\subsubsection{Average emission rates}

ERs can be used to compare the overall impact of vehicular emissions on near-roadway communities across freeways. Total pollutant emission rates for four freeways were computed using Eq. (2). Daily VMT per freeway mile within Los Angeles (and the fraction due to HDD) during the 215 working days from 1 December 2010-30 November 2011 were used to generate average hourly emission rates, plotted in Fig. 5. (Daily time series for VMT and HDD and LDG VMT are shown in Fig. S4 in the Supplement.) The error bars represent the standard deviation due to daily variation in VMT. Except for a summer-to-fall increase in port related goods movement on I-710, there were no significant seasonality aspects to consider (see Fig. S5 in the Supplement). While average fuel efficiency was used to calculate ERs and changes in fuel efficiency due to difference in driv- ing conditions were not taken into account, it is likely that changes in efficiency would be similar across freeways and that a comparison based on average fuel efficiency is applicable because the diurnal profile of speed on freeways is similar (see Fig. S6 in the Supplement). It worth noting that we did not resolve EFs by speed and likely understated emissions during rush hours where speed is most reduced and stop-and-go conditions occur, but these diurnal differences in speed in Los Angeles are also very similar across freeways (see Fig. S6 in the Supplement).

Figure 5 shows that while I-710 has often been studied and observed as a high end of freeway emissions (Fruin et al., 2008), ER results indicate that on per mile of freeway basis among the freeways compared, currently the highest emitting freeway is SR-91, due to both high VMT and relatively high HDD fraction, and that emissions per mile from I-110 and I-405 are roughly comparable to I-710 for $\mathrm{NO}, \mathrm{NO}_{\mathrm{x}}$ and PN. The above discussion illustrates that the common assumption - that freeways with the highest truck volume fractions are the worst sources of pollution - may be too simple. Total VMT on several low-fraction HDD freeways in Los Angeles are now high enough for total emissions to be comparable to I-710. As an additional illustration, in Fig. 6 the NO ERs have been plotted against total VMT (vehicle miles per mile of freeway during May 2011) for two freeways, I-710 and I405. Despite much lower HDD fraction on I-405 compared to I-710 (3.8\% versus $12 \%)$, total emissions were comparable for almost all hours of the day. Figure 6 shows that hypothetically reducing HDD fraction by more than two-thirds on I-710 would likely provide little if any total NO reductions, if VMT were simultaneously doubled. Hence, while HDD fraction is an important factor in determining overall freeway ER, at currently high Los Angeles VMT levels, LDG contributions to total freeway emissions can be comparable to HDD. Furthermore, continuing future VMT growth will likely offset much of the emissions reduction benefits of a cleaner HDD fleet. 


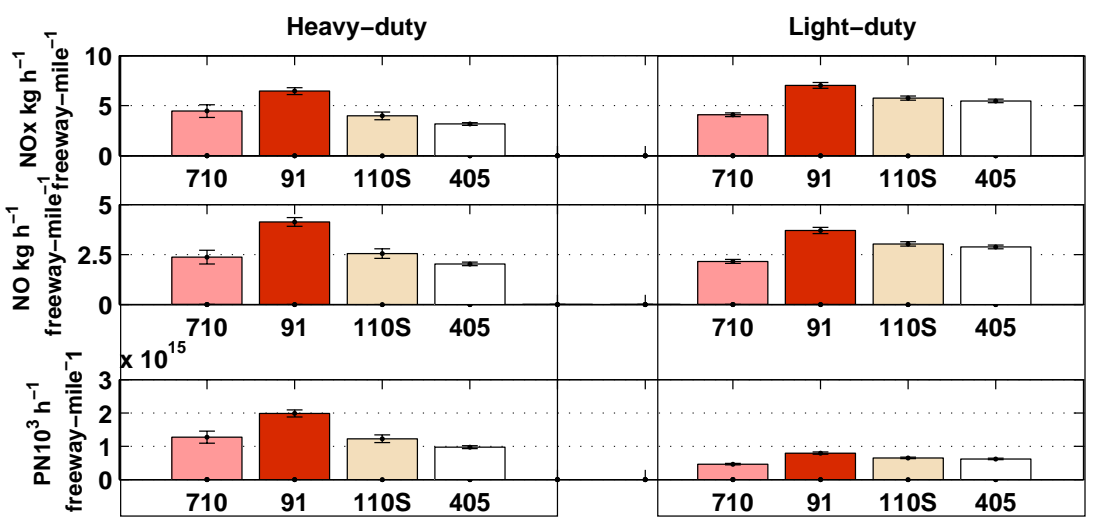

Fig. 5. Average hourly freeway emission rates for four freeways within LA County lines. 110S refers to I-110, the southern segment with mixed fuel fleet.

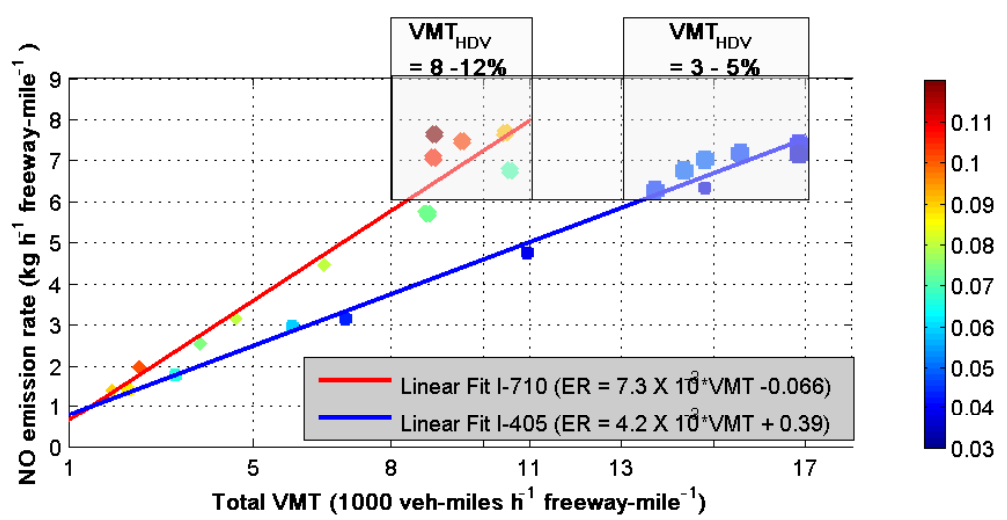

Fig. 6. Comparison of NO emission rates for a low (I-405) and high (I-710) HDD fraction freeway. The color bar indicates the fraction of total VMT attributable to HDD.

\section{Conclusions}

Emission factors estimated using data collected with a mobile measurement platform during real-world driving conditions and across multiple freeways suggest that diesel fueled heavy duty vehicle (HDD) emission factors still exceed gasoline fueled light duty vehicle (LDG) emission factors (EFs) by an order of magnitude, but HDD EFs are decreasing relatively rapidly. Measurements also showed that to further lower emissions from HDD, regulations that target a fleet-wide reduction would be most suitable for $\mathrm{NO}_{\mathrm{x}}$ and NO, while significant reductions for particulate species (BC, PN, PB-PAHs) may still be attained through targeting specific high emitters. Our results also suggest that emission factors for HDD on I-710, the major cargo traffic corridor in Los Angeles, have dropped enough to remove its distinction as the freeway with the worst air quality, due to additional regulations targeting goods movement and promoting accelerated fleet turnover. However, HDD fleet-wide NO emissions on I-710 have decreased without any significant differences in $\mathrm{NO}_{\mathrm{x}}$ emissions, suggesting an increase in $\mathrm{NO}_{2}$ emissions, perhaps due to the adoption of continuously-regenerating particle trap control technology (Heeb et al., 2011; Velders et al., 2011). An implication of this result (i.e., continuously regenerating technology retrofits are both increasing $\mathrm{NO}_{2}$ and decreasing particulate matter) is that $\mathrm{NO}_{2}$ may no longer be an accurate metric of diesel particulate matter. When studywide mean EFs were used to calculate total emissions from freeways, emissions from I-710, I-110 and 1-405 appeared to be comparable, despite a 3-fold range in HDD fraction. This underscores the importance of taking total vehicle activity into account when considering regional freeway air quality impacts. The assumption that freeways with the highest HDD fractions are significantly worse sources of total emissions may need reexamination in Los Angeles.

\section{Supplementary material related to this article is available online at: http://www.atmos-chem-phys.net/13/ 347/2013/acp-13-347-2013-supplement.pdf.}

Acknowledgements. This work was funded by the California Air Resources Board through contract number 07-310. The statements and conclusions in this article are those of the authors and not 
necessarily those of the California Air Resources Board. Authors would also like to acknowledge the NIEHS grant 1K25ES01922401 and US EPA STAR program grant RD-8324-1301-0 to the University of Southern California.

Edited by: X. Querol

\section{References}

Ban-Weiss, G. A., McLaughlin, J. P., Harley, R. A., Lunden, M. M., Kirchstetter, T. W., Kean, A. J., Strawa, A. W., Stevenson, E. D., and Kendall, G. R.: Long-Term Changes in Emissions of Nitrogen Oxides and Particulate Matter from On-Road Gasoline and Diesel Vehicles, Atmos. Environ., 42, 220-232, 2008.

Ban-Weiss, G. A., Lunden, M. M., Kirchstetter, T. W., and Harley, R. A: Measurement of black carbon and particle number emission factors from individual heavy-duty trucks, Environ. Sci. Technol., 43, 1419-1424, 2009.

Ban-Weiss, G. A., Lunden, M. M., Kirchstetter, T. W., and Harley, R. A.: Size-resolved particle number and volume emission factors for on-road gasoline and diesel motor vehicles, J. Aerosol Sci., 41, 5-12, 2010.

Bishop, G. A. and Stedman, D. H.: A decade of on-road emissions measurements, Environ. Sci. Technol., 42, 1651-1656, 2008.

Bishop, G. A., Peddle, A. M., Stedman, D. H., and Zhan, T.: Onroad emission measurements of reactive nitrogen compounds from three California cities, Environ. Sci. Technol., 44, 36163620, 2010.

Bishop, G. A., Schuchmann, B., Stedman, D. H., and Lawson, D. R.: Emission Changes Resulting from the San Pedro Bay, California Ports Truck Retirement Program, Environ. Sci. Technol., 46, 551-558, 2012.

Brunekreef, B., Beelen, R., Hoek, G., Schouten, L., BauschGoldbohm, S., Fischer, P., Armstrong, B., Hughes, E., Jerrett, M., and van den Brandt, P.: Effects of long-term exposure to trafficrelated air pollution on respiratory and cardiovascular mortality in the Netherlands: the NLCS-AIR study, Research Report Health Effects Institute, 139, 73-89, 2009.

California Air Resources Board (CARB): Estimated Annual Average Emissions, http://www.arb.ca.gov/ei/emissiondata.htm, 2009.

California Air Resources Board (CARB): ARB's Drayage Truck Regulatory Activities, http://www.arb.ca.gov/msprog/onroad/ porttruck/porttruck.htm, 2011a.

California Air Resources Board (CARB) Research Division: California Motor Vehicle Emission Factor/Emission Inventory Model, http://www.arb.ca.gov/msei/modeling.htm, 2011b.

California Department of Transportation (CALTRANS) Traffic Data Branch: Annual Average Truck Counts, http: //traffic-counts.dot.ca.gov/2009all/docs/2009truckpublication. pdf, 2009.

Choe, T., Skabardonis, A., and Varaiya, P.: Freeway performance measurement system (PeMS): an operational analysis tool, Journal of the Transportation Research Board, 1181, 67-75, 2002.

Dallmann, T. R., Harley, R. A., and Kirchstetter, T. W.: Effects of Diesel Particle Filter Retrofits and Accelerated Fleet Turnover on Drayage Truck Emissions at the Port of Oakland, Environ. Sci. Technol., 45, 10773-10779, 2011.
Dallmann, T. R., DeMartini, S. J., Kirchstetter, T. W., Herndon, S. C., Onasch, T. B., Wood, E. C., and Harley, R. A: On-Road Measurement of Gas and Particle Phase Pollutant Emission Factors for Individual Heavy-Duty Diesel Trucks, Environ. Sci. Technol., 46, 8511-8518, 2012.

Fruin, S., Westerdahl, D., Sax, T., Sioutas, C., and Fine, P. M.: Measurements and predictors 30 of on-road ultrafine particle concentrations and associated pollutants in Los Angeles, Atmos. Environ., 42, 207-219, doi:10.1016/j.atmosenv.2007.09.057, 2008.

Harley, R. A., Marr, L. C., Lehner, J. K., and Giddings, S. N.: Changes in motor vehicle emissions on diurnal to decadal time scales and effects on atmospheric composition, Environ. Sci. Technol., 39, 5356-5362, 2005.

Heeb, N. V., Zimmerli, Y., Czerwinski, J., Schmid, P., Zennegg, M., Haag, R., Seiler, C., Wichser, A., Ulrich, A., Honegger, P., Zeyer, K., Emmenegger, L., Mosimann, T., Kasper, M., and Mayer, A.: Reactive nitrogen compounds (RNCs) in exhaust of advanced $\mathrm{PM}-\mathrm{NO}_{\mathrm{x}}$ abatement technologies for future diesel applications, Atmos. Environ., 45, 3203-3209, 2011.

Hudda, N., Cheung, K., Moore, K. F., and Sioutas, C.: Intercommunity variability in total particle number concentrations in the eastern Los Angeles air basin, Atmos. Chem. Phys., 10, 11385-11399, doi:10.5194/acp-10-11385-2010, 2010.

Jiang, M., Marr, L. C., Dunlea, E. J., Herndon, S. C., Jayne, J. T., Kolb, C. E., Knighton, W. B., Rogers, T. M., Zavala, M., Molina, L. T., and Molina, M. J.: Vehicle fleet emissions of black carbon, polycyclic aromatic hydrocarbons, and other pollutants measured by a mobile laboratory in Mexico City, Atmos. Chem. Phys., 5, 3377-3387, doi:10.5194/acp-5-3377-2005, 2005.

Kean, A. J., Harley, R. A., and Kendall, G. R.: Effects of vehicle speed and engine load on motor vehicle emissions, Environ. Sci. Technol., 37, 3739-3746, 2003.

Kirchstetter, T. W. and Novakov, T.: Controlled generation of black carbon particlesfrom a diffusion flame and applications in evaluating black carbon measurementmethods, Atmos. Environ., 41, 1874-1888, 2007.

Kirchstetter, T. W., Harley, R. A., Kreisberg, N. M., Stolzenburg, M. R., and Hering, S. V.: On-road measurement of fine particle and nitrogen oxide emissions from light- and heavy-duty motor vehicles, Atmos. Environ., 33, 2955-2968, 1999.

Kuhn,T., Biswas, S., Fine, P. M., Geller, M., and Sioutas, C.: Physical and chemical characteristics and volatility of PM in the proximity of a light-duty vehicle freeway, Aerosol Sci. Tech., 39, 347-357, 2005a.

Kuhn, T., Biswas, S., and Sioutas, C.: Diurnal and seasonal characteristics of particle volatility and chemical composition in the vicinity of a light-duty vehicle freeway, Atmos. Environ., 39, 7154-7166, 2005b.

Marr, L. C., Gogan, L. A., Wöhrnschimmel, H., Molina, L. T., Molina, M. J., Smith, T. J., and Garshick, E.: Vehicle Traffic as a Source of Particulate Polycyclic Aromatic Hydrocarbon Exposure in the Mexico City Metropolitan Area, Environ. Sci. Technol., 38, 2584-2592, 2004.

Niessner, R.: The Chemical Response of the Photoelectric Aerosol Sensor (Pas) to Different Aerosol Systems, J. Aerosol Sci., 17, 705-714, 1986.

Ntziachristos, L., Ning, Z., Gellar, M., and Sioutas, C.: Particle concentration and characteristics near a major freeway with heavyduty diesel traffic, Environ. Sci. Technol., 41, 2223-2230, 2001. 
Park, S. S., Kozawa, K., Fruin, S., Mara, S., Hsu, Y., Jakober, C., Winer, A., and Herner, J.: Emission Factors for High-Emitting Vehicles Based on On-Road Measurements of Individual Vehicle Exhaust with a Mobile Measurement Platform, J. Air Waste Manage., 61, 1046-1056, 2011.

Port of Long Beach (PoLB), Port of Los Angeles (PoLA): San Pedro Bay Ports Clean Air Action Plan: About the Clean Air Action Plan, http://www.cleanairactionplan.org/about_caap/default.asp, 2010a.

Port of Long Beach (PoLB), Port of Los Angeles (PoLA): 2010 update San Pedro Bay Ports clean air action plan, http://www.cleanairactionplan.org/civica/filebank/blobdload. asp?BlobID=2474, 2010b.

Velders, G. J. M., Geilenkirchen, G. P., and de Lange, R.: Higher than expected $\mathrm{NO}_{\mathrm{x}}$ emission from trucks may affect attainability of $\mathrm{NO}_{2}$ limit values in the Netherlands, Atmos. Environ., 45, 3025-3033, 2011.

Wenzel, T., Singer, B. C., and Slott, R. S.: Some issues in the statistical analysis of vehicle emissions, Journal of Transportation and Statistics, 3, 31-14, 2000.
Westerdahl, D., Fruin, S., Sax, T., Fine, P. M., and Sioutas, C.: Mobile platform measurements of ultrafine particles and associated pollutant concentrations on freeways and residential streets in Los Angeles, Atmos. Environ., 39, 3597-3610, 2005.

Zavala, M., Herndon, S. C., Slott, R. S., Dunlea, E. J., Marr, L. C., Shorter, J. H., Zahniser, M., Knighton, W. B., Rogers, T. M., Kolb, C. E., Molina, L. T., and Molina, M. J.: Characterization of on-road vehicle emissions in the Mexico City Metropolitan Area using a mobile laboratory in chase and fleet average measurement modes during the MCMA-2003 field campaign, Atmos. Chem. Phys., 6, 5129-5142, doi:10.5194/acp-6-5129-2006, 2006.

Zavala, M., Herndon, S. C., Wood, E. C., Jayne, J. T., Nelson, D. D., Trimborn, A. M., Dunlea, E., Knighton, W. B., Mendoza, A., Allen, D. T., Kolb, C. E., Molina, M. J., and Molina, L. T.: Comparison of emissions from on-road sources using a mobile laboratory under various driving and operational sampling modes, Atmos. Chem. Phys., 9, 1-14, doi:10.5194/acp-9-1-2009, 2009. 